\title{
Editorial special issue on cyanobacterial blooms and water ecological restoration
}

\author{
Ming $\mathrm{Li}^{1} \cdot$ Xiangdong $\mathrm{Bi}^{2} \cdot$ Renhui $\mathrm{Li}^{3}$ \\ Published online: 28 September 2020 \\ (C) Springer-Verlag GmbH Germany, part of Springer Nature 2020
}

Cyanobacterial bloom formation and aquatic ecosystem degradation driven by global warming and eutrophication have become serious ecological and environmental problems worldwide. Recently, great progress in physiology of cyanobacteria has been achieved, but our knowledge on the mechanisms of bloom formation of cyanobacterial species and the feasible methods for ecological restoration is still poor.

The 6th Forum on Cyanobacterial Blooms, organized by the Northwest Agriculture and Forest University, Yangling, China, in 22-23 June 2019, was held to share most recent research progress in cyanobacterial blooms and ecological restoration around China. This forum was held annually since 2014. The forum was jointly proposed and initiated by Prof. Guoxiang Wang from Nanjing Normal University and Prof. Renhui Li from the Institute of Hydrobiology, Chinese Academy of Sciences. Since then, the form has covered a wide variety of topics, including the most common toxic bloomforming cyanobacterium Microcystis, cyanobacteria blooms and nutrient cycling in shallow lakes, interactions between cyanobacterial bloom formation and physical, chemical, and biological factors, as well as monitoring and early warning of cyanobacterial blooms.

This Special Issue of Environmental Science and Pollution Research comprises selected papers presented in the 6th Forum on Cyanobacterial Blooms. In detail, 13 communications are presented in this special issue, elucidating the following topics:

Responsible editor: Philippe Garrigues

Ming Li

lileaf@nwsuaf.edu.cn; lileaf@163.com

1 College of Natural Resources and Environment, Northwest A\&F University, Yangling 712100, People's Republic of China

2 College of Fishery, Tianjin Agricultural University, Tianjin 300384, People's Republic of China

3 College of Life and Environmental Science, Wenzhou University, Wenzhou 325035, China

\section{Phytoplankton and bacterioplankton community}

Wei et al. (2020) compared the variation in annual phytoplankton community responding to varying environmental factors in two urban landscape lakes. This work is potentially interesting because artificial lakes with shorter formed time were investigated while most literatures related to phytoplankton community variation focused on natural lakes or reservoirs. Du et al. (2020) investigated the bacterioplankton spatial distribution patterns and its determinants in a typical urban lake in eastern China (West Lake) by 16S rRNA gene highthroughput sequencing. A feasibility study on the pigment composition method evaluating phytoplankton composition (CHEMTAX-HPLC method) was carried out from a river system (Weihe River, Northwest China) and suggested that CHEMTAX-HPLC method was not accurate enough to characterize the phytoplankton communities in the freshwater ecosystem (Tian et al. 2019). Long et al. (2020) illustrated that morphology-based functional groups of phytoplankton could be an effective biological water quality indicator based on a case study in the Pearl River, South China.

\section{Microcystis colony formation and structure}

Li et al. (2020) reported that the extract of aquatic macrophyte Carex cinerascens induced colony formation in the bloomforming cyanobacterium Microcystis and suggested that plant allelopathy was one of the major factors contributing to colony formation in Microcystis. The material basis of Microcystis colony formation was always considered as extracellular polysaccharides. Zu et al. (2020) found that cell wall surface layer (S-layer) would also be the material basis promoting colony formation in Microcystis by comparison of S-layer characteristics between colonial and unicellular forms of Microcystis and function conformation. Wu et al. (2020) optimized a method for measuring the compactness of Microcystis 
colonies and made insight into the relationships between the volume ratio of cells to the colony and floating velocity of various sized colonies. Their results suggested that compactness may be an active regulation strategy for Microcystis colonies to promote buoyancy.

\section{Cyanobacterial blooms and ecological restoration in Lake Taihu, China}

Chen et al. (2020) investigated the variation in the area of cyanobacterial blooms in Lake Taihu after a typhoon employing a 6-year field investigation in Lake Taihu and satellite data analysis. They found that short-term nutrient release during a typhoon did not result in an obvious increase in Microcystis cell density but the horizontal migration of Microcystis colonies would be the reason why the area of a cyanobacterial bloom increases in Lake Taihu after a typhoon passes. Qi et al. (2020) focused on the concentration and characterization of odorants in Lake Taihu and found that the concentration in the water of cyanobacterial blooms zones was approximately 3 to 21 times higher than that in macrophyte-dominated zones. An outdoor mesocosm water ecological restoration experiment was conducted in Lake Taihu by Han et al. (2019), and their results suggested that it was necessary to continuously remove the juvenile benthivorous fish several times for restoring the submerged macrophytes in shallow lakes.

\section{Algal physiology and cultivation in the laboratory}

Bai et al. (2020) studied the interspecific competition between Cylindrospermopsis raciborskii and Microcystis aeruginosa on different phosphorus substrates in laboratory and indicated that advantages for $C$. raciborskii would be dominated in natural waters with dissolved inorganic phosphorus limitation or dissolved organic phosphorus. Zhang et al. (2020) studied the response of extracellular and intracellular alkaline phosphatase activity (APA) of Microcystis to $\beta$-glycerol-phosphate ( $\beta$-GP) and lecithin (LEC). They indicated that Microcystis in the LEC groups could secret more extracellular APA compared with the $\beta$ GP treatment. Yan et al. (2020) used Monte Carlo method to simulate the illumination distribution inside a cylindrical photobioreactor for wastewater treatment. Their approach provides new insights for improving the efficiency and scalability of photobioreactors for wastewater treatment to reduce nutrient input and slow eutrophication in reservoirs and lakes.

In summary, the field investigations focusing on phytoplankton community and laboratory experiments studying algal physiology were carried out frequently, and researches on cyanobacterial bloom control and ecological restoration are still needed for better management of our drinking water supplies.

Acknowledgments The authors would like to thank the Guangzhou BOSMA Ind Co., Ltd, Nanjing Hoan Environmental Monitoring Co., Ltd., Beijing Gaowo Law Firm, Hexi University, and Tang Scholar Project by the Cyrus Tang Foundation supporting this conference. The authors would also like to thank Ms. QQ Jiang, Dr. JY Zhang, Dr. JM Deng, and Dr. X Man supporting for conference affairs.

\section{References}

Bai F, Shi JQ, Yang SQ, Yang YJ, Wu ZX (2020) Interspecific competition between Cylindrospermopsis raciborskii and Microcystis aeruginosa on different phosphorus substrates. Environ Sci Pollut Res. https://doi.org/10.1007/s11356-020-08652-0

Chen HM, Zhu YY, Zhang Y, Chen XQ, Wang RC, Zhu W (2020) Cyanobacterial bloom expansion caused by typhoon disturbance in Lake Taihu China. Environ Sci Pollut Res. https://doi.org/10.1007/ s11356-020-09292-0

Du Y, Yang W, Ding XY, Zhang JJ, Zheng ZM, Zhu JY (2020) High heterogeneity of bacterioplankton community shaped by spatially structured environmental factors in West lake, a typical urban lake in Eastern China. Environ Sci Pollut Res. https://doi.org/10.1007/ s11356-020-08818-w

Han YQ, Gu J, Li QS, Zhang Y, He H, Shen RJ, Li KY (2019) Effects of juvenile crucian carp (Carassius carassius) removal on submerged macrophytes growth - implications for subtropical shallow lake restoration. Environ Sci Pollut Res. https://doi.org/10.1007/s11356019-07217-0

Li L, Jing XL, Wang L, Zeng ZG, Chen WH, Zhai JH, Qi SQ (2020) The extract of aquatic macrophyte Carex cinerascens induced colony formation in bloom-forming cyanobacterium Microcystis aeruginosa. Environ Sci Pollut Res. https://doi.org/10.1007/ s11356-020-08651-1

Long SX, Zhang T, Fan JJ, Li C, Xiong KN (2020) Responses of phytoplankton functional groups to environmental factors in the Pearl River, South China. Environ Sci Pollut Res. https://doi.org/10. 1007/s11356-020-08344-9

Qi C, Fang JQ, Wang GX, Huang HX, Wang ZS, Si ZJ, Zhang LM (2020) Characterization of odorants in contrasting ecotypes of Lake Taihu: algae-dominated versus macrophyte-dominated zones. Environ Sci Pollut Res. https://doi.org/10.1007/s11356-020-078960

Tian YQ, Gao L, Deng JM, Li M (2019) Characterization of phytoplankton community in a river ecosystem using pigment composition: a feasibility study. Environ Sci Pollut Res. https://doi.org/10.1007/ s11356-019-07213-4

Wei J, Wang M, Chen CT, Wu HM, Lin L, Li M (2020) Seasonal succession of phytoplankton in two temperate artificial lakes with different water sources. Environ Sci Pollut Res. https://doi.org/10. 1007/s11356-020-10387-X

Wu HM, Yang TT, Wang CB, Tian CC, Donde OO, Xiao BD, Wu XQ (2020) Co-regulatory role of Microcystis colony cell volume and compactness in buoyancy during the growth stage. Environ Sci Pollut Res. https://doi.org/10.1007/s11356-020-08250-0

Yan ZJ, Liu J, Qian L, Xu WL, Yuan Z, Zhao CX (2020) Development and validation of a photobioreactor for uniform distribution of light intensity along the optical path based on numerical simulation. Environ Sci Pollut Res. https://doi.org/10.1007/s11356-02007987-y 
Zhang TX, Lu XR, Yu RD, Qin MY, Wei C, Hong SJ (2020) Response of extracellular and intracellular alkaline phosphatase in Microcystis aeruginosa to organic phosphorus. Environ Sci Pollut Res. https:// doi.org/10.1007/s11356-020-09736-7

Zu Y, Hong SJ, Xu CX, Li WW, Chen SY, Li JH (2020) Cell wall surface layer (S-layer) promotes colony formation in Microcystis: comparison of S-layer characteristics between colonial and unicellular forms of Microcystis and function conformation. Environ Sci Pollut Res. https://doi.org/10.1007/s11356-020-08254-w

Publisher's note Springer Nature remains neutral with regard to jurisdictional claims in published maps and institutional affiliations.

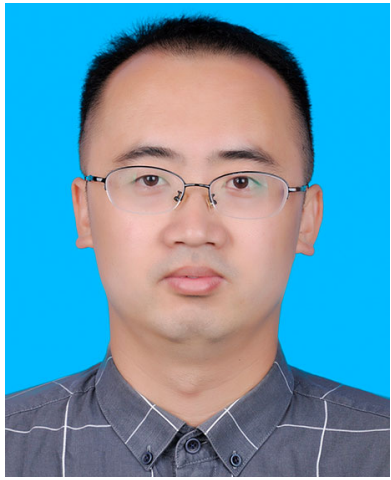

Ming Li received a B.E. in Hydrology at Hohai University (Nanjing, China) in 2008 and a $\mathrm{Ph} . \mathrm{D}$. degree in Environmental Science and Engineering at Hohai University in 2013. He then worked at Northwest Agriculture and Forest University as a lecturer and was promoted to full professor in 2018. He is expert in phycology, hydrology, aquatic ecology, soil and water conservation, and algal biotechnology. He has published over 80 papers in peer-reviewed journals. He is funded as a Tang Scholar by the Cyrus Tang Foundation. He is serving as a board member of Journal of Lake Sciences (since 2019). Email address: lileaf@nwsuaf.edu.cn; lileaf@163.com(Ming Li)

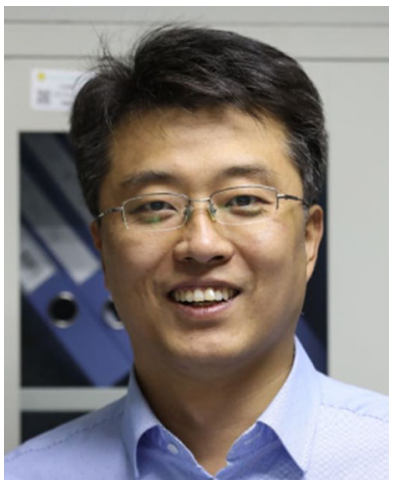

Xiangdong Bi received a B.S. in Marine Biology at Liaoning Normal University in 2006 (Dalian, China) and a Ph.D degree in Marine Biology at Ocean University of China (Qingdao, China) in 2013. He was engaged in teaching and scientific research at College of Fishery in Tianjin Agricultural University (Tianjin, China) as an assistant professor (2008) and was then promoted to associate (2013) and full professor (2018). In the meantime, he was engaged in postdoctoral research at Nankai University (Tianjin, China: 2014-2016). He has published over 40 papers in peer-reviewed journals. He received First level talents of Tianjin "131" innovative talents training project (2018), China's 100 excellent postdoctoral science foundation recipients (2016), first prize of China commercial science and technology Progress Award (2019), second prize of science and technology progress award of Liaoning Province (2018), and three prize of science and technology progress award of Tianjin City (2015). E-mail: yl801123@aliyun.com

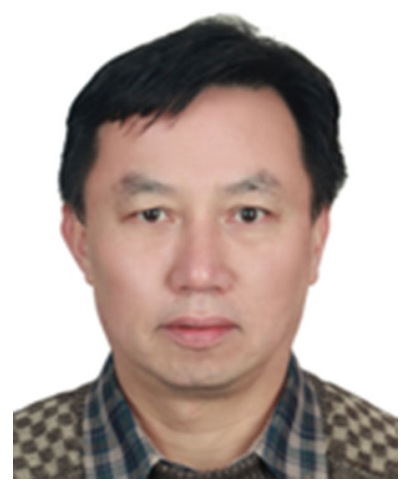

Renhui Li is a Professor at College of Life and Environmental Sciences, Wenzhou University. He got his $\mathrm{Ph}$. D at University of Tsukuba, Japan, in 1998, and conducted his postdoc researches during 1999-2005 at Wright State University, Virginia Tech, and University of Tennessee, respectively. He was awarded as the Hundred Talents Program of Chinese Academy of Sciences (CAS) and became a PI leading a research group on Biology of Harmful Algae in Institute of Hydrobiology, CAS, in 2005. His research has focused on the diversity, ecology, and harmful metabolites (cyanotoxins and taste and odor, etc.) of cyanobacteria. He moved to Wenzhou University in January 2020. He has published over 100 papers in peer-review international journals, and he is serving as an associate editor of "Phycologia" and a board member of "Harmful Algae." Email: reli@ihb.ac.cn or renhui.li@wxu.edu.cn, Mobile: +86-13037177100 